This is an electronic reprint of the original article. This reprint may differ from the original in pagination and typographic detail.

Author(s): Moate, Josephine; Ruohotie-Lyhty, Maria

Title: Identity, agency and community: reconsidering the pedagogic responsibilities of teacher education

Year: $\quad 2014$

Version:

Please cite the original version:

Moate, J., \& Ruohotie-Lyhty, M. (2014). Identity, agency and community:

reconsidering the pedagogic responsibilities of teacher education. British Journal of Educational Studies, 62(3), 249-264. https://doi.org/10.1080/00071005.2014.955456

All material supplied via JYX is protected by copyright and other intellectual property rights, and duplication or sale of all or part of any of the repository collections is not permitted, except that material may be duplicated by you for your research use or educational purposes in electronic or print form. You must obtain permission for any other use. Electronic or print copies may not be offered, whether for sale or otherwise to anyone who is not an authorised user. 


\title{
Identity, agency and community: reconsidering the pedagogic responsibilities of teacher education
}

\begin{abstract}
This article presents a model for teacher education based on an ongoing action research project at a Finnish university. This model draws on the educational theory of Dewey and the pedagogical sensibility of Bakhtin to critically consider the concepts of teacher identity and agency and to highlight the role of community in teacher development. Our aim is to propose a model that supports the development of new directions in teacher education that would better prepare teachers to face the challenges in their future work by engaging with the educational community in the present.
\end{abstract}

\section{Key words:}

identity, agency, community, teacher education, pedagogic responsibility

A thought that, like a fish in an aquarium, knocks against the bottom and the sides and cannot swim farther or deeper. Bakhtin, 1981, p. 162

\section{Introduction}

This paper draws on the pedagogic sensibility of Bakhtin’s dialogic theory (e.g. 1981, 1986, 1993) and the educational theory of Dewey (e.g. 1933, 1938) to outline a new direction for teacher education today. Our concern is that teacher education tends to either limit pre-service 
teacher development by over-emphasizing practice or by over-emphasizing theory. The government policy in England for post-graduate teacher training, for example, emphasizes school-based practice as the central feature of pre-service training. In contrast, Finnish educational policy requires a university-based Master’s degree for all teachers (Sahlberg, 2011; FNBE, 2011) with emphasis on theoretical knowledge. The different orientations of these two systems are further reiterated by a comparison of policy documentation with standards of achievement on the one hand (e.g. DfE, 2013) and the values and principles of education on the other (e.g. FNBE, 2011). This paper does not intend to further pursue a comparison between these two systems, but to use these examples to highlight how pre-service teachers participant in different ways in different teacher education contexts.

The key issues that we would like to highlight with regard to existing models of teacher education focus on the forms of participation offered in teacher education and the relationship between theory and practice. In the current climate of educational reform, considerations about standards (DfE, 2013) and individual development (cf. Beauchamp and Thomas, 2009) draw attention away from the role of the educational community and forms of participation within the community. In recent years attempts have been made to address issues of teacher development with a significant amount of attention being paid to identity and agency work. Whilst identity and agency work recognise the important dimensions of who and how in education, the further dimensions of with whom and why are often absent. In our understanding, being in the world inevitably involves an ongoing interaction between the individual and the environment, however, this is a mutual relationship neither dependent on the individual nor environment alone (Dewey, 1933; Bakhtin, 1993). 
In this paper we outline one way in which educational theory and practice can be brought together in teacher education to address the concerns of not only who and how, but also with whom and why. Following a brief review of different ways in which identity and agency have been viewed in educational research, we bring the notion of community into the discussion to suggest a more complex conceptualisation of teacher education. Our model for pre-service teacher development is then introduced along with a practical illustration of this model in use. It should be noted at this point that we are not suggesting that this model is generalisable to all contexts. In a more Deweyan spirit we hope that "the more we can share in the experiences of others, the more resources we will have for dealing with our problems, and hence the more intelligent our collective problem solving will [hopefully] be” (Biesta and Burbules, 2003, p.70).

\subsection{Here and now in teacher education}

The pedagogical sensibility of Bakhtin’s dialogic theory largely comes from his moral philosophy on what it means to be an individual in relation to other. For Bakhtin, each individual occupies a unique place in space and time meaning that each individual has a unique contribution to the open-ended project of life together (Bakhtin, 1993; Emerson, 1996). This standpoint emphasises the responsibility we each have to make our contribution and that alone we are incomplete, in other words we need to engage with others to gain a broader understanding of the world (Emerson, 1996). Bakhtin’s moral philosophy, in our view, complements Dewey’s transactional view in which the relationship between each individual and the environment is reciprocal and active: I act upon the world as the world acts upon me and we are both changed in the process. For Dewey “experience is ... the very way in which living organisms are connected 
with reality” (Biesta and Burbules, 2003, p.28) and it is through experience that the world can be gradually understood.

Both Dewey and Bakhtin view individuals and development through engagement with other, whether the wider environment or other individuals. Neither philosopher took it for granted, however, that authentic or beneficial engagement was automatic. For Bakhtin, each individual has to choose whether to submit to external authorities and to "pretend" to exist (Bakhtin, 1986; Emerson, 1996) or to take up personal responsibility. For Dewey, each individual is anyway in the world and although thinking is natural, it is not necessarily intelligent. It is the privilege of education to help individuals to go beyond habitually being in the world to intelligently thinking and acting in the world. The word "intelligent" highlights the Deweyan principle to critically consider different options before acting, to imaginatively and deliberatively consider the purposes and possible consequences of different actions (Dewey, 1922; Biesta and Burbules, 2003). From this perspective, through intelligent thought, contemporaneous action and reflection appropriate predispositions to act are formed and understanding of the world develops.

Whilst on paper this account seems relatively straightforward, Dewey offers no guarantees that knowledge gained through intelligent participation is the final “truth”. Rather than seek a final answer, however, Dewey appears to be more interested in the integrity of the process and the verification of understanding. "Intelligent thoughts" are worth little if they do not work in the world, on the other hand action without thought is all the more likely to sustain habitual rather than improved being in the world. The critical implications of these perspectives for teacher education are addressed throughout the paper. 


\subsection{Identity and agency in teacher development}

Contemporary educational research suggests that teachers use their understanding of self to make sense of their environment (Coldron and Smith, 1999). Professional identities are recognized to be teachers’ understanding of themselves as professionals (Eteläpelto and Vähäsantanen, 2008), including personal and institutional aspects of being a teacher (Beijaard, Meijer and Verloop, 2004). As teachers face increasing instability of environments due to educational diversity, educational reforms (Ketelaar et al., 2012) innovations and transitions (Czerniawski, 2011), this instability is similarly mirrored in the instability of professional identities. Although environmental change can positively enrich teacher identities and pedagogic repertoires (e.g. Guskey, 2002), the possibility also exists that change can reduce both teacher identities and pedagogic repertoires (Moate, 2011a). Novice teachers in particular can face profound identity

crises when transitioning from pre-service to in-service contexts (Ruohotie-Lyhty, 2013; Thomas and Beauchamp, 2011; Hong, 2010).

One response to this crisis has been to focus on notions of personal and professional identity. Emphasis has increasingly been placed on teachers' ability to reflect on previously held beliefs and to develop their professional selves in different contexts (Eteläpelto and Vähäsantanen, 2008; Beijaard et al., 2004) with discontinuous self-experiences unified in one teacher story through constant inner negotiation (Akkerman and Meijer, 2011). A number of practical methods have been introduced in pre-service education to support identity reflection and the formation of a more thorough understanding of self. These methods include the guided use of action research (Freese, 2006), the sharing of teachers' autobiographical stories (Le Fevre, 2011) and the use of metaphors (Thomas and Beauchamp, 2011). Despite these innovations, 
teacher education still does not appear to provide adequate support for identity development (Ruohotie-Lyhty, 2013).

As with the notion of identity, agency has been the subject of wider interest in teacher development and teacher education (Biesta and Tedder, 2007; Eteläpelto, et al., 2013). Agency is recognised as teachers' ability to enact pedagogical convictions and understanding of what is educationally beneficial. Moreover, the notion of teacher agency highlights the complexity of education and the required sensitivity of educators. Complex classroom situations can rarely be resolved by applying methodological guidelines or theoretical generalizations. Individual pupils are always more than a particular type of learner and each individual comes with a unique story (van Manen, 1991; Gutierrez and Rogoff, 2003). A significant dilemma facing teacher education, however, is how to support prospective teachers to act as educators in the present in order to be educators in the future (Lipponen and Kumpulainen, 2011; Heikkinen, Tynjälä and Kiviniemi, 2011).

It is perhaps because of this dilemma that some models of teacher education tend to train teachers to deliver the curriculum and to plan lessons, rather than to deal with complex classroom situations (e.g. Edwards and D’Arcy, 2004). If student teachers are misled to believe that education is technical and that this belief is reinforced with a sense of accountability (Raiker and Rautiainen, 2014), we question whether the pedagogical sensitivity and intelligent thought required of educators is developed. The situation in Finland is somewhat different with different theoretical conceptualisations and considerations of education introduced from the outset. Ironically in our context it is the teacher practice school that is more problematic. 
University practice schools were initially established along Deweyan lines to provide a school in which student teachers could authentically engage with the practical side of education providing a context for the enactment and critical reflection on educational theory. Currently the university school in our context comprises grades 1-12 and approximately 1000 pupils and on an annual basis 900 student teachers complete practices there. As few field schools participate in teacher education and the practice school receives government funding to fulfil its function, it is perhaps unsurprising that the practice school differs from other schools in Finland. The practice school is, for example, better resourced than other schools and enjoys the reputation of being a good school. Nevertheless, the participation of student teachers is limited in significant ways. The practice school pupils, for example, are relatively expert at working with novice teachers and the class or subject teacher is always present. The flux of teachers means that textbooks mediate pedagogic and social actions to maintain continuity between teachers. It can perhaps be suggested that the school community is so well-prepared for working with pre-service teachers that the student teachers do not actually participate as educators. Indeed, with so many student teachers completing practices within the school it is difficult to see how else the system could work, but ironically it is the efficiency of the system which arguably undermines the purpose of the school. As a result, practice periods can all too easily become periods of apprenticeship into the existing culture of the practice school, rather than an opportunity to critically practice theoretical understanding. Within the Finnish context, it is therefore perhaps possible to say that whilst teacher education strives to encourage intelligent thought the separation from authentic practice is most disconcerting.

In both of the scenarios outlined above, student teachers appear to knock against glass walls within teacher education. If practice is overly- and authoritatively prioritised student 
teachers may not even swim in the richer waters of educational theory preventing them from "seeing familiar objects in a new light and thus opening new vistas in experience” (Dewey, 1933, p.278). On the other hand, if students are encouraged to "intelligently think" yet lack the freedom to act, the development of their disposition as educators may be severely curtailed. Within our context attempts are being made to create greater space in teacher education for inquiry-based education (Lipponen and Kumpulainen, 2011) with student teachers encouraged to pursue different educational phenomena. If, however, understanding is not freely verified in practice, the thought of student teachers merely "knocks against the bottom and the sides and cannot swim farther or deeper".

The argument that we are beginning to make here is that teacher identity and agency can only develop if pre-service teachers are given the opportunity to authentically participate as teachers which means having a degree of autonomy and responsibility for others in addition to self (Ruohotie-Lyhty and Moate, 2014). Our concern is that despite efforts to support teacher reflection in pre-service contexts the restrictive environment prevents not only teacher identity development but also the development of understanding. Research within teacher education has similarly found that structural guidelines, such as accountability and grading, foster particular stances suggesting that pre-service teachers' identity and agency are rooted in responses to immediate authority (Mäensivu, Nikkola and Moilanen, 2013; Raiker and Rautianen, 2014). If this is the case, the opportunities for pre-service teachers to think and act intelligently in the context of teacher education are, therefore, of the utmost importance. For Dewey, being and doing are so profoundly interlinked that it is only through action and experience that understanding can develop. 


\subsection{Bringing community to the fore}

The concerns we have raised here rather starkly point to the role of the community in teacher education. The surrounding community is important as the "control of individual actions is effected by the whole situation in which individuals are involved, in which they share and of which they are co-operative or interacting parts” (Dewey, 1938, p. 53). Furthermore, "the limitation ... put upon outward action ... put a great restriction upon intellectual and moral freedom” (Dewey, 1938, p. 61). This raises the question of how the community of teacher education engages with and invites the participation of student teachers: are prospective teachers given the opportunity to deliberate yet not allowed to act? Are prospective teachers required to act without the opportunity to deliberate? Dewey goes on to say that,

Community life does not organize itself in an enduring way purely spontaneously. It requires thought and planning ahead. The educator is responsible for a knowledge of individuals and for a knowledge of subject-matter that will enable activities to be selected which lend themselves to social organization, an organization in which all individuals have an opportunity to contribute something, and in which the activities in which all participate are the chief carrier of control. (1938, p.56)

This depiction of community life highlights the responsibility of teacher education to provide a community environment that supports the building of multiple bridges with and between individuals, different educational communities, educational theory and practice within the present and for the future.

Arguably the way in which we know and the way in which we come to know have significant implications for the way in which we live (Palmer, 1987). Furthermore, those with whom we come to know carry a significant degree of responsibility for how we come to live and this is why we have to consider what kind of community offers necessary encounters for teacher 
development. Students introduced to sociological problems through figures and generalized abstractions struggle to understand the lived experience of a child from a difficult background and fail to recognize that they share the responsibility for shaping the world we share. In Palmer's words, “epistemology tends to become an ethic and that every way of knowing tends to become a way of living...the relation established between the knower and the known, between the student and the subject tends to become the relation of the living person to the world itself... every model of knowing contains its own moral trajectory, its own ethical direction and outcomes” (Palmer, 1987). Palmer's conclusion is that current ways of knowing in higher education all too easily educate students out of the world, rather than into it. We doubt that the university context isolated from the wider world can provide the necessary encounters that allow for authentic deliberation, action and reflection. It is at this point that we would like to introduce our model for teacher education.

\section{A theoretical model for teacher education}

On the basis of the theoretical review presented above, our model for teacher education builds on our understanding of Dewey's theory of learning and Bakhtin’s pedagogic sensibility. The ongoing relationship between thinking and acting is central in this model, a relationship that we suggest should come to the fore when designing a teacher education community.

Figure 1. A teacher education model based on Dewey’s theory of education

Having introduced the key concepts that form the basis of our teaching philosophy we now focus on the practical initiatives we have taken in the implementation and development of this 
model. To provide the context for these examples we describe Finnish teacher education in a little more detail and the specific teacher education programme within which our initiative takes place.

\subsection{Finnish teacher education as a space for research based innovations}

The Finnish educational sector has a number of special features. These features include the absence of a private educational sector and the high level of autonomy enjoyed by individual teachers. This is partly based on the requirement of a Master's degree to qualify as a teacher and the esteem in which the Finnish teaching profession is regarded (Sahlberg, 2011). Teacher autonomy is possibly greater in higher education as teacher educators, for example, are expected not only to teach but to also research their own practices and significant freedom is given for research-based innovations. Finnish teacher education strives to build on problem- and researchbased approaches to education. At the University of Jyväskylä these tendencies are currently taken further with the emphasis on phenomenon-based curriculum and working practices. The core idea of this development is to identify with students the core phenomena in education and to elaborate on these themes through critical inquiry. This development hopes to get overcome the compartmentalisation of knowledge-building and instead using one phenomenon as a doorway into various questions about and dimensions of education. These current developments frame the initiatives introduced in this article. Our model corresponds with the bigger process of change at our university as well as building on our previous research on teacher development (RuohotieLyhty, 2013; Moate, 2011b; Ruohotie-Lyhty and Moate, 2014). The particular context for our model, however, is the JULIET programme introduced below.

\subsection{JULIET as a teacher education programme and as a research project}


The Jyväskylä University Language Innovation and Educational Theory -programme (JULIET) is one line of class teacher education offered by the Department of Teacher Education. The JULIET programme annually accepts 12 class teacher students wishing to specialize in English teaching in addition to their class teacher qualification. This programme continues over a period of five years and offers early foreign language pedagogy courses as well as language development courses integrated with basic and advanced courses in education. JULIET was established as a teaching programme in 1995, transforming into an explicit action research project in 2013. This transformation required the JULIET staff to take up the Deweyan challenge of intelligent deliberation, action and reflection as teacher educators and to share our "warranted assertions” with the wider community of teacher education.

\section{Conceptualising education through experience: the phenomenon of diversity}

To concretize our approach the following section of the paper outlines the way in which one of the integrated themes in the first year class teacher programme has been engaged with in the JULIET programme. In a globalized world teachers' cultural sensitivity and ability to encounter and discuss difference are of great importance. For this reason, diversity is one of the integrated themes of teacher education at the University of Jyväskylä. Through the presentation of this example, we hope to highlight how the concepts of identity, agency and community are enacted through concrete working methods planned in cooperation with the student teachers.

\subsubsection{An academic approach to diversity in society}

The phenomenon of diversity was most explicitly dealt with in the 5ects Sociology of Education course. As part of this course the student teachers read several articles working with the theme 
within a sociological context and discussed the most important questions in small groups in which the teacher educator was partly present. The students were involved in selecting the texts that were read and for the course assignment the student teachers independently chose a topic related to multicultural education. Using the themes addressed in the readings, as well as seeking for additional literature, the course participants wrote an argumentative essay on the topic. This assignment was read by the teachers and students were given individual written feedback on their writing.

In this context, identity development is linked to student teachers’ possibilities to critically consider their previously held beliefs about diversity and to form understanding about the responsibility of a teacher as a multicultural educator. The agency of the students can be seen in the selection of readings and in their freedom to choose and develop an argumentative text from their own standpoint. This rather typical way of approaching a theme within teacher education, however, did not fully correspond with our understanding of how student teachers could profoundly consider their identity through agentic action in community in relation to diversity. We therefore sought other opportunities to act in our surroundings that could potentially take place alongside this more theoretical activity: to offer the students the opportunity to intelligently think about the questions related to multiculturalism and diversity and to verify their ideas through community interactions during the first year of their studies.

\subsubsection{Initiative 1: Meeting immigrant adults}

The Sociology of Education course began with the teacher educator suggesting the students exchange ideas with a group of people from different backgrounds. As the student teachers had little contact with immigrants in the town, the teacher educator contacted the educational services 
to form a contact with the Finnish teaching groups organized by the municipality. The first meeting with the group of immigrants learning Finnish was organized towards the beginning of the sociology course to enable student teachers to discuss the ideas they had formed on the basis of the initial readings. Before the meeting the students produced questions together and these questions were sent to the Finnish group beforehand to give the immigrant participants time to look at the question with their teacher. In the actual meeting the participants divided into small groups to discuss Finnish multiculturalism and diversity experiences. The experiences of the meeting were later reflected on in a group meeting as well as in the learning journals of the students.

Later in the semester, the student teachers wanted to organize another meeting with the same group of immigrants. This meeting was organized as part of the Educational Psychology course. In this meeting the immigrants and teacher students shared their significant life experiences in the form of photos and stories. Extracts from the students’ learning journals are included below to give a sense of the way in which the students responded to these encounters.

\footnotetext{
This was our second meeting with immigrants, and I enjoyed as much as last time. Actually, I saw the chance to work with immigrants even more valuable now - after writing my argumentative essay during the course of sociology. Usually there are hardly any opportunities to encounter students with ethnic background in teacher education, which leads to lack of multicultural professionalism of teachers. (From a student's learning journal)

It seemed to be pretty important for immigrants that we could follow their stories even though their Finnish was sometimes difficult to understand. By asking questions and making short "summaries" of their stories discussion flowed nicely forward. I still had to remind myself to talk clearly - without too many dialectal words- so that immigrants could understand what I am trying to say. Furthermore, body language became a handy way to express myself. Indeed, I consider body language to be important tool in every classroom since there are students with various learning styles. (From a student's learning journal)
}

These meetings provided student teachers with the opportunity for self-development through conscious reflection on others. Furthermore, we hope that these encounters provide the student teachers with the possibility of developing their understanding and multicultural identities 
contemporaneously going beyond theoretical conceptualisations that anticipate possible future encounters.

\subsubsection{Initiative 2: Diversity in photos - project and discussions with American student teachers}

To link the student teachers reading with their own current context, student teachers were asked to look for diversity in their own environment and to photograph these representations in order to share them in Facebook with another student group. Having agreed on this plan, the teacher educator and student participants decided to contact other universities to seek for a partner group for this activity. A group of student teachers in America was willing to join this activity and a Finnish student created a closed group in Facebook in which the American and Finnish photos were shared and commented on by the course participants. The commenting in Facebook was followed by a Skype discussion organized in small groups with Finnish and American student participants. As the American and Finnish contexts were different, the photos also presented different manifestations of the phenomenon.

\footnotetext{
I think also the term culture (for example in multiculturalism) is very interesting. On our lesson today, initially most of us connected it with countries and nationalities. After bringing up religion to the discussion, it became clear that cultures can be so much more. Isn't for example Braille language part of the sight impaired peoples culture and so on? I wonder where the thought that cultures should be related to nationalities and so on actually stems from. (A student's comment in the Facebook group)

We had a nice talk about differences about recess time in Finland and in USA. I had never thought how beneficial the recess could be before they told us about the ADHD problems they were having. After all it is common sense that the students can pay attention far better if they can spend their energy in recess and have a little break for brains too. (From a student's learning journal after the Skype meeting with the American students)
}

In this initiative, the main goal was to become sensitive to diversity in the habitual environment through photography and by gaining a new perspective through the eyes of an outsider (Bakhtin, 1986). As with the earlier initiative, this activity offered the student participants the opportunity to develop broader understandings through contemporaneous engagement with others. 


\subsubsection{Initiative 3: Teaching groups of English speaking pupils}

During the spring semester the student teachers were also offered the opportunity to voluntarily participate in the teaching of primary pupils that had English as a mother tongue although they lived in Finland. The city of Jyväskylä offers children with a mother tongue other than Finnish a 90 minute lesson on a weekly basis outside of the main school timetable. These classes aim to support the children's language skills and cultural identity. All the students volunteered to participate and actively developed a range of activities to use with the children. Taking responsibility for these children provided the students with the opportunity to engage in teaching and to be proactive in a multicultural community.

Mother tongue classes have offered us a great opportunity to try out theories and methods in real setting! (...) Children are challenging to work with since you can't be sure how they react or act. Experience among various groups helps. (From a student's reflective essay at the end of the semester)

This initiative positioned the student teachers differently when compared with the previous examples in which encounters were related to a specific phenomenon. When engaging to teach these children, the student teachers were not just responsible for themselves but they were invited to voluntarily take responsibility for other people. Instead of designing with the teacher educator encounters that could enable their learning, they were invited to think what they had to offer to other people.

\subsection{Identity, agency and community}

By sharing these initiatives, we hoped to illustrate how our model developed for teacher education has supported our practical actions and reflections on both the theory and practice of our work as teacher educators. In our opinion the development of student teachers' identity and agency as multicultural educators can only begin in a community with real opportunities for practical and theoretical engagement with the phenomenon coupled with genuine participation 
within the community. As we have critically reflected on these educational initiatives we have seen the importance of the community and the reciprocal relationship between the students and their environment in a new light.

These initiatives highlight the way in which intelligent thinking and the process of verification of thought requires a wider community. In our experience the development of student teachers as multicultural educators cannot take place within the "aquarium" of the university context alone. In this case, the meetings with the immigrant adults and Englishspeaking children as well with groups of international teacher students were crucial for the student teachers' development process strengthening connections between who they are (identity), what they do and can do (agency) and with whom they are (community). Social media provided the possibility to create communities of sharing and practice that were not limited to immediate surroundings or directly controlled by teacher educators. In this kind of learning process, the student teachers relationship with their educators and other people is of great importance. When student teachers were sharing their experiences and life narratives with the immigrants and teaching the children in the English classes, they had the possibility to act as responsible actors instead of being only accountable to their educators. We see this voluntary engagement as a precondition for all deeply meaningful learning processes.

\section{Discussion}

In this article we have presented a model of teacher education that is part of a larger curriculum change in a Finnish university. This model is based on reconsideration of the central concepts of identity and agency in the light of Bakhtinian and Deweyan thought. Building on these foundations we have attempted to highlight possibilities for contemporaneous identity and 
agency development within teacher education. Through our engagement with educational theory and practice, we recognise and would like to stress the need for greater acknowledgement of the role community plays in teacher education. Instead of building our teacher education practices on competence standards or considerations on important contents in an attempt to predetermine what kind of teachers our students should become, we want to invite them to engage them with the "why" questions of education. For us, the crucial question is, in which kind of communities student teachers can both intelligently think about their previously held beliefs and at the same time experientially test these models in practice. In our opinion this requires opening teacher education towards the world beyond the university context without forfeiting our responsibilities as teacher educators. With the help of the existing communication media, experiential learning possibilities do not have to be limited to immediate surroundings nor to the conventional “aquarium” of an academic classroom, but student participation and community formation can take previously impossible forms.

Previous studies on teacher development, suggest that agency within a community offers different kind of options for professional learning as well as explaining differences in teacher contentment (Kelchtermans and Ballet, 2002; Ruohotie-Lyhty, 2009). This implies that teacher education should also reconsider the notion and extensiveness of community, and the forms of participation provided by the community. Although participation in the community learning processes remains voluntary, the duty of educators relies on the opportunities that the certain community offers for proactive participation. By this we mean a form of participation that is not only a response to somebody else's initiatives, but a genuine recognition of personal responsibility in the world (Emerson, 1996; Ruohotie-Lyhty and Moate, 2014). We believe that this kind of agency can only take place when groups of students are given the opportunity to 
engage in planning processes, that is in the "intelligent thought" of teacher education. Critical decisions on important themes and working methods cannot, therefore, be made by teacher educators alone, but need to be taken together with the student teachers. Teacher education can also provide and encourage possibilities for voluntary engagement with the world. When offering our students with the possibility to participate into a voluntary teaching practice with multicultural students, we were surprised by the students' eagerness to take this proactive step. This clearly contrasts with our experiences of student teacher lack of responsibility within mandatory courses where they are accountable mostly to their teacher educator (Mäensivu, et al., 2013).

The approach described in this article also demands a change in the teacher educator role. Instead of a specialist, the one who knows better, the teacher educator becomes a community builder recognising the responsibilities of teacher educator without filling the space or predefining the whole space to be occupied by student participants (Lipponen and Kumpulainen, 2011). This kind of role necessitates openness towards opportunities that are offered by the immediate surrounding and also sensitivity towards student teachers' community building initiatives. As teacher educators we also acknowledge that it is our responsibility to continue to seek an intelligent, deliberating approach for teacher education. As part of this quest we have presented here a model based on our previous research and existing theories that we are currently living and testing. The data that we are gathering through these activities can help us to critically reflect on our role as teacher educators. We consider this important for the further development of our work and in maintaining an on-going conversation with the wider community, although we do not anticipate a final solution. 
Furthermore, we are beginning to recognise that careful deliberation around what we are offering our student teachers, why and how - as well as looking around to see with whom we are working has also helped us to start to see the student teachers in a new light. We wonder whether in the near future we will begin to refer to our student teachers as contributors in the wider discussion around education, rather than participants in teacher education. This resonates with the openness to research based initiatives in Finnish teacher education although perhaps uncomfortably challenges the conventional university practice in Finland. Although this model or our practical methods are not directly applicable to other teacher education contexts, we believe that they can offer an important opportunity to review and to reflect on teacher education beyond our context as well.

\section{References}

Akkerman, S. F. and Meijer, P. C. (2011) A dialogical approach to conceptualizing teacher identity, Teaching and Teacher Education, 27, 308-319.

Bakhtin, M. M. (1981) (translated from the Russian by C. Emerson and M. Holquist) The Dialogic Imagination: Four Essays (Austin, University of Texas Press).

Bakhtin, M. M. (1986) Speech genres and other late essays (No. 8). (Austin, University of Texas Press).

Bakhtin, M. M. (1993) (translated from the Russian by V. Liapunov) Toward a Philosophy of the Act (Austin, University of Texas Press).

Beauchamp, C., \& Thomas, L. (2009) Understanding teacher identity: An overview of issues in the literature and implications for teacher education, Cambridge Journal of Education, 39 (2), 175-189. 
Beijaard, D., Meijer, P. and Verloop, N. (2004) Reconsidering research on teachers’ professional identity, Teaching and Teacher Education, 20 (2), 107-128.

Biesta, G. and Burbules, N. C. (2003) Pragmatism and Educational Research (Lanham, Rowman and Littlefield).

Biesta, G. and Tedder, M. (2007) Agency and learning in the lifecourse: Towards an ecological perspective, Studies in the Education of Adults, 39 (2), 132-149.

Coldron, J., and Smith, R. (1999) Active location in teachers' construction of their professional identities. Journal of Curriculum Studies, 31 (6), 711-726.

Czerniawski, G. (2011) Emerging teachers-emerging identities: trust and accountability in the construction of newly qualified teachers in Norway, Germany, and England, European Journal of Teacher Education, 34 (4), 431-447.

Department for Education (DfE). (Revised June 2013). Teachers’ standards.

Dewey, J. (1922) Human Nature and Conduct. In J. A. Boydston (Ed) The Middle Works 18991924, (vol. 14) (Carbondale, Southern Illinois University Press).

Dewey, J. (1933) How We Think: A Restatement of the Relation of Reflective Thinking to the Educative Process. In J. A. Boydston (Ed) In The Later Works 1925-1953, (vol. 4) (Carbondale: Southern Illinois University Press).

Dewey, J. (1938/1997) Experience and Education (Touchstone: New York).

Edwards, A. and D'Arcy, C. (2004) Relational agency and disposition in sociocultural accounts of learning to teach, Educational Review, 56 (2), 147-155.

Emerson, C. (1996). Keeping the self intact during the culture wars: A centennial essay for Mikhail Bakhtin. New Literary History, 27 (1), 107-126. 
Eteläpelto, A. and Vähäsantanen, K. (2008) Ammatillinen identiteetti persoonallisena ja sosiaalisena konstruktiona [Professional identity as a personal and social construction]. In A. Eteläpelto and J. Onnismaa (Eds) Ammatillisuus ja ammatillinen kasvu. Aikuiskasvatuksen 46. vuosikirja. (Helsinki: Kansanvalistusseura), 26-49.

Eteläpelto, A., Vähäsantanen, K., Hökkä P. and Paloniemi S. (2013) What is agency? Conceptualizing professional agency at work, Educational Research Review, 10, 45-65.

Finnish National Board of Education (FNBE) (2011) Learning and Competence 2020 Strategy of the Finnish National Board of Education (FNBE, Helsinki).

Freese, A. R. (2006) Reframing one's teaching: Discovering our teacher selves through reflection and inquiry, Teaching and Teacher Education, 22 (1), 100-119.

Guskey, T. R. (2002) Professional development and teacher change, Teachers and Teaching:theory and practice, 8 (3), 381-391.

Gutiérrez, K. D., \& Rogoff, B. (2003) Cultural ways of learning: Individual traits or repertoires of practice. Educational researcher, 32 (5), 19-25.

Heikkinen, H. L., Tynjälä, P., and Kiviniemi, U. (2011) Integrative pedagogy in practicum. In M. Mattsson, T. V. Eilertsen and D. Rorrison (Eds) A practicum turn in teacher education (Rotterdam: Sense Publishers), 91-112.

Hong J. Y. (2010) Pre-service and beginning teachers’ professional identity and its relation to dropping out of the profession, Teaching and Teacher Education, 26, 1530-1543.

Kelchtermans, G., \& Ballet, K. (2002) The micropolitics of teacher induction: A narrativebiographical study on teacher socialisation. Teaching and Teacher Education, 18 (1), 105120. 
Ketelaar, E., Beijaard, D., Boshuizen, H. P. A. and Den Brok, P. J. (2012) Teachers’ positioning towards an educational innovation in the light of ownership, sense making and agency, Teaching and Teacher Education, 28, 273-282.

Le Fevre, D. M. (2011) Creating and facilitating a teacher education curriculum using preservice teachers’ autobiographical stories, Teaching and Teacher Education, 27, 779-787.

Lipponen, L., and Kumpulainen, K. (2011) Acting as accountable authors: Creating interactional spaces for agency work in teacher education. Teaching and Teacher Education, 27 (5), 812-819.

Moate, J. M. (2011a) The impact of foreign language mediated teaching on teachers' sense of professional integrity in the CLIL classroom, European Journal of Teacher Education, 34 (3), 333-346.

Moate, J. (2011b) Voicing the challenges faced by an innovative teacher community, Teachers and Teaching: Theory and Practice, 17 (2), 255-268.

Mäensivu, M., Nikkola, T. and Moilanen, P. (2013) Students constructing the curriculum - An experiment to increase responsibility. In C. Nygaard, N. Courtney and P. Bartholomew (Eds) Quality Enhancement of University Teaching and Learning (Oxfordshire: Libri Publishing), 19-35.

Palmer, P. J. (1987). Community, conflict, and ways of knowing: Ways to deepen our educational agenda. Change: The Magazine of Higher Learning, 19 (5), 20-25.

Raiker, A. and Rautiainen, M. (2014) Framing the ethical landscape in education: Finnish and English perspectives on teachers' moral selves. In D. Jindal-Snape and E. Hannah (Eds) Exploring the dynamics of personal, professional and interprofessional ethics (Policy Press, Bristol), 217-231. 
Ruohotie-Lyhty, M. and Kaikkonen, P. (2009) The difficulty of change: the impact of personal school experience and teacher education on the work of beginning language teachers. Scandinavian Journal of Educational Research, 53 (3), 295-309.

Ruohotie-Lyhty, M. (2011) Constructing practical knowledge of teaching: eleven newly qualified language teachers' discursive agency. The Language Learning Journal, 39 (3), $365-379$.

Ruohotie-Lyhty, M. (2013) Struggling for a professional identity: Two newly qualified language teachers' identity narratives during the first years at work. Teaching and Teacher Education, 30, 120-129.

Ruohotie-Lyhty, M., \& Moate, J. (2014). Proactive and reactive dimensions of life-course agency: mapping student teachers’ language learning experiences. Language and Education, (ahead-of-print), 1-16.

Raiker, A. and Rautiainen, M. (2014) Framing the professional and interprofessional ethical landscape in education: Finnish and English perspectives on teachers’ moral selves. In D. Jindal-Snape and E. G. F. Hannah (Eds) Exploring the Dynamics of Personal, Professional and Interprofessional Ethics, 217-223.

Sahlberg, P. (2011) Finnish Lessons: What Can the World Learn from Educational Change in Finland? (New York, Teachers College Press).

Thomas, L. and Beauchamp, C. (2011) Understanding new teachers’ professional identities through metaphor, Teaching and teacher Education, 27, 762-769.

Van Manen, M. (1991) The tact of teaching: The meaning of pedagogical thoughtfulness (New York, SUNY Press). 
